University of Louisville

ThinkIR: The University of Louisville's Institutional Repository

Electronic Theses and Dissertations

$12-2010$

\title{
Gender role stereotypes in advertising : a test of the match-up hypothesis on advertising effectiveness.
}

Sara Picklesimer

University of Louisville

Follow this and additional works at: https://ir.library.louisville.edu/etd

\section{Recommended Citation}

Picklesimer, Sara, "Gender role stereotypes in advertising : a test of the match-up hypothesis on advertising effectiveness." (2010). Electronic Theses and Dissertations. Paper 1136.

https://doi.org/10.18297/etd/1136

This Master's Thesis is brought to you for free and open access by ThinkIR: The University of Louisville's Institutional Repository. It has been accepted for inclusion in Electronic Theses and Dissertations by an authorized administrator of ThinkIR: The University of Louisville's Institutional Repository. This title appears here courtesy of the author, who has retained all other copyrights. For more information, please contact thinkir@louisville.edu. 


\title{
GENDER ROLE STEREOTYPES IN ADVERTISING A TEST OF THE MATCH-UP HYPOTHESIS ON ADVERTISING EFFECTIVENESS
}

\author{
By \\ Sara Picklesimer \\ B.S., University of Louisville, 2007
}

\begin{abstract}
A Thesis
Submitted to the Faculty of the Graduate School of the University of Louisville in Partial Fulfillment of the Requirements for the Degree of
\end{abstract}

Master of Arts

Department of Communication University of Louisville

Louisville, KY

December 2010 



\title{
GENDER ROLE STEREOTYPES IN ADVERTISING A TEST OF THE MATCH-UP HYPOTHESIS ON ADVERTISING EFFECTIVENESS
}

\author{
By \\ Sara Picklesimer \\ B.S., University of Louisville, 2007
}

A Thesis Approved on

November 19, 2010

By the following Thesis Committee:

Thesis Director 


\section{ABSTRACT \\ GENDER ROLE STEREOTYPES IN ADVERTISING: \\ A TEST OF THE MATCH-UP HYPOTHESIS ON ADVERTISING EFFECTIVENESS}

SARA PICKLESIMER

DECEMBER 16, 2010

Images in advertisements often depict social expectations for gendered behavior, reinforcing stereotypical masculine and feminine behaviors. This study examined the effectiveness of using gender role stereotypical images in advertisements by matching two products with a male and female, based on the match-up hypothesis. Two gender congruent and two gender incongruent advertisements were created to test the effectiveness of gender congruency on perceived message clarity, advertisement believability, perceived argument quality, attitude toward the advertisement, attitude toward the brand, and purchase intention, based on the information-processing model.

Though gender congruent advertisements were perceived as slightly more effective than the gender incongruent advertisements, perceived message clarity was the only variable significantly influenced by gender congruency as messages in gender congruent advertisements were perceived as more clear than those in gender incongruent advertisements. Therefore, this study serves to encourage advertisers to re-evaluate current advertising techniques, as they are currently reinforcing gender stereotypical behaviors for little benefit 
PAGE

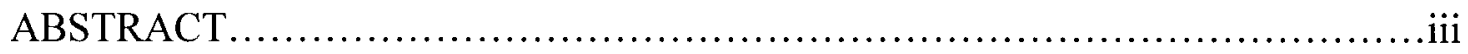

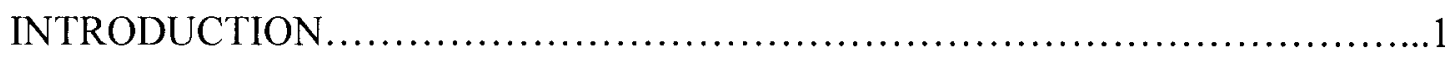

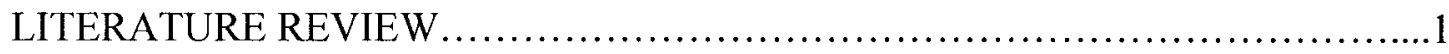

Hypotheses........................................................... 10

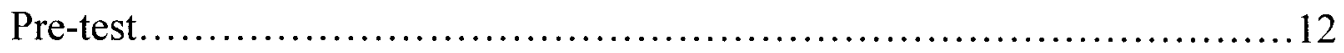

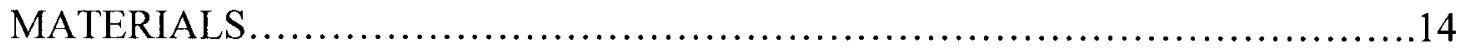

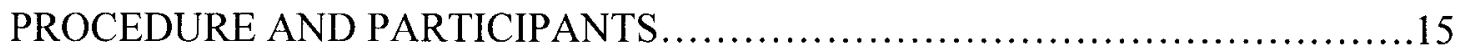

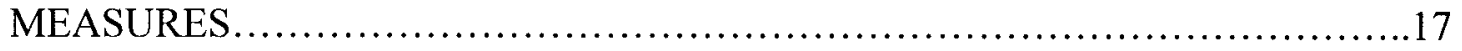

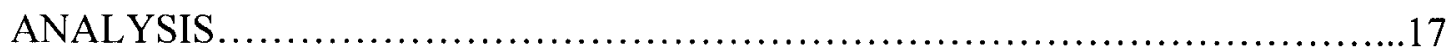

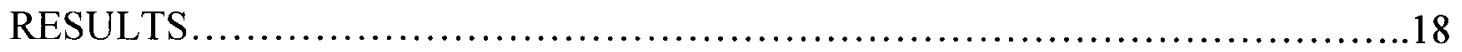

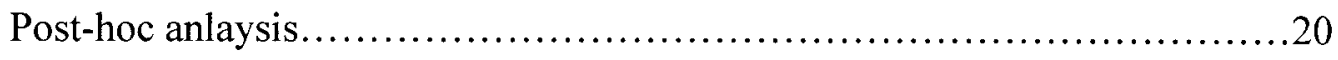

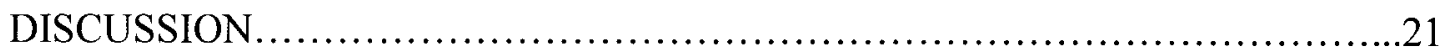

LIMITATIONS AND FUTURE RESEARCH.................................27

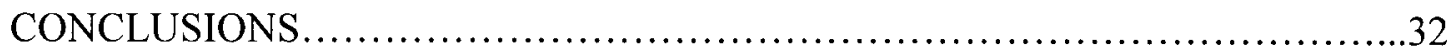

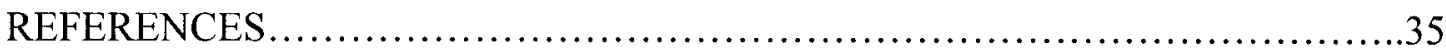

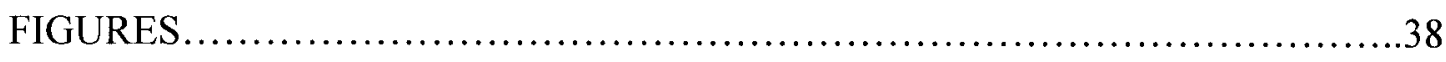

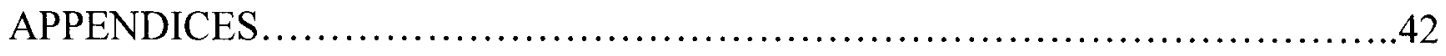

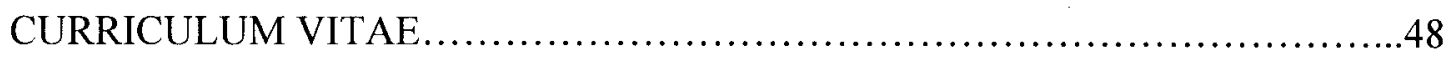




\section{INTRODUCTION}

Gender role stereotypes are existent all around us, even still in contemporary society. Though society has shown progression toward equality between men and women, outdated ideas still exist about the roles men and women should and do embody. The media is no exception, specifically in the area of advertising. By pairing men and women with gender congruent products, these stereotypes are further reinforced. This study will examine the match-up hypothesis as it relates to gender congruency with products in advertisements, and the effects these advertisements have on perceived message clarity, advertisement believability, perceived argument quality, attitude toward the brand and advertisement, and purchase intention. The research is guided by one overarching research question and six central hypotheses.

\section{LITERATURE REVIEW}

Sut Jhally, professor of communication at the University of Massachusetts and founder and Executive Director of the Media Education Foundation, once said, "To not be influenced by advertising would be to live outside of culture. No human being lives outside of culture" (Kilbourne, 1999). No matter how often we deny the effect that advertising has on us as individuals and as a society, the evidence remains. The average American is exposed to at least 3,000 advertisements each day, with ads making up nearly $70 \%$ of newspapers and $40 \%$ of our mail (Kilbourne, 1999). Though we may not pay attention to every last ad we see, there is no doubt that it is nearly impossible to tune 
out all of the information with which we are bombarded, especially when this type of media is specifically designed to break through the clutter. We currently live in a world that is increasingly saturated by the media, as well as other information and communication technologies; we also live in a world that is stratified based on gender, race, ethnicity, class, age, sexuality, etc. in which an evident power struggle exists. Advantages and disadvantages associated with each of these categories are unevenly distributed, making some groups and individuals more easily targetable and susceptible to advertising's messages (Gill, 2007).

"Advertisers spend enormous amounts of money on psychological research and understand addiction at least as well as, if not better than, any other group in the country. They use this knowledge to target children (because if you hook them early, they are yours for life), to encourage all people to consume more, in spite of often dangerous consequences for all of us, and to create a climate of denial in which all kinds of addictions flourish" (Kilbourne, 1999). Advertising fosters an environment in which addictions run rampant, reinforcing beliefs that products can provide companionship when we are otherwise devoid of human connection. We live in a materialistic culture where great consumers are the ones who often feel some sort of emptiness. Our significant relationships become those that exist with a product, like an iPod, Blackberry, cigarettes, alcohol, food, etc. Though it may not be the advertisers' intent to objectify women, sexualize children, or encourage eating disorders and alcoholism, these are often unfortunate side effects of the images presented. Advertising turns people into objects, using them to sell products, often by packaging and presenting certain body parts, and presenting that image to consumers (Kilbourne, 1999). For example, many ads for 
women's razors and other shaving products feature only the thin, sleek, and tanned image of a woman's legs with no cuts or bandages. Other ads for skin care or shaving products may show the woman's legs being caressed by a man or by her, giving the impression that smooth legs is the key to a successful relationship which is the key to happiness.

What is so frightening, however, is that human beings are actually the products being sold to advertisers and we do not even realize what is going on. Advertising is one of the most important aspects of mass media - maybe even the most important aspect - as advertising supports more than $60 \%$ of magazine and newspaper production and almost $100 \%$ of electronic media (Kilbourne, 1999). Denying that we are unaffected seems nearly ridiculous when we consider that advertisers spend approximately $\$ 200$ billion a year on advertising (Kilbourne, 1999). Rance Crain, the Editor-in-Chief of Advertising Age magazine claimed, "Only eight percent of an ad's message is received by the conscious mind; the rest is worked and re-worked deep within the recesses of the brain, where a product's positioning and repositioning takes shape" (Kilbourne, 1999). Certainly we can argue that these messages and images go by unnoticed, but they are not ineffective as advertising is subliminal, and gender is one of the key factors that advertisers take into account when creating ad campaigns.

According to Jhally (Gill, 2007), gender ideology is the single biggest resource for advertisers. Therefore, the prevalence of gender role stereotypes in advertisements, and in the media in general, is important to examine as the media and the ads play a role in not only reflecting culture, but also perpetuating the way people should act within a culture. Advertising, then, is not just a mirror of society but "is both a creator and perpetuator of the dominant attitudes, values, and ideology of the culture, the social 
norms and myths by which most people govern their behavior" (Kilbourne, 1999). Here, the role of social learning plays a part, as an image is really all an advertisement has to sell. According to Hovland et al. (2005), as people are repeatedly exposed to advertising images, they internalize the advertiser's view of themselves and of others.

Advertisements are everywhere, and the more images people see and the more frequently they see the images, the more the audience identifies with the images.

The images of gender role stereotypes in advertising have been criticized since before the 1970s and the Women's Movement. Courtney \& Lockeretz (1971) and Wagner \& Banos (1973) found that women were most often seen in advertisements for cleaning products, drugs, clothing, and home appliances, and men were more often seen in ads for cars, travel, alcoholic beverages, cigarettes, and banks. The stereotypes that traditionally characterize men and women are manifest in distinct psychological and physiological traits, as well as in domains of action. Women are seen as emotional and slender, associated with the household, family, and fashion, while men are seen as muscular and competent, associated with paid work, sports, and technology (Carter \& Steiner, 2004; Doring \& Poschl, 2006). In her book Can't Buy My Love, Jean Kilbourne recalls a 1968 ad for Ovulen-21, a birth control pill. The main image was the head of a woman with the headline "Ovulen-21 works the way a woman thinks - by weekdays... not 'cycle days'." The woman's head was filled with seven pictures, each representing one day of the week where the pictures representing a day included items like a laundry basket and an iron, suggesting that a woman's week consisted only of household chores. (Kilbourne also claims that the ad suggests that women were too stupid to remember their 
cycles, but could remember the days of the week because they consisted only of a continuous cycle of chores, but that is outside the scope of this paper.)

Though women today may be free from this stereotypical domestic lifestyle, the images seen then and now can still have a great impact. From a cultivation theory perspective, similar to social learning, people tend to incorporate stereotypes presented in the media into their own concepts of reality. This causes people to change their existing concepts of reality to match what is portrayed in the media, eventually resulting in a change in behavior (Gerber \& Gross, 1973; Doring \& Poschl, 2006). It is evident, then, that gender role stereotypes are reflections of society and resources of model behavior for certain characteristics. According to McLaughlin \& Goulet (1999) (Doring \& Poschl, 2006), expectations implied by advertising regarding gender role stereotypes can be seen as socialization agents for three reasons. First, advertisements are broadcast publicly, so they influence all members of society. Second, models in the ads convey acceptance of their roles and thus validate those roles. Third, advertisements serve to educate viewers of acceptable and unacceptable behaviors and define social expectations through their portrayals of roles and attitudes of both men and women.

Social interactionists and identity theorists posit that shared meanings are constructed through social interaction, and one's perceived social location is in reference to others. Connell (1987) argued that gender identity is an individual's most significant identity. Though individuals may use other people as sources of reliable information to maintain and validate identities, the media has a central position in the daily lives of consumers which practically ensures that information and images disseminated by the 
media become points of interaction with individuals in a given society (Milkie, 1994; Mastin, et al., 2004).

Erving Goffman (1979) used frame analysis to examine gender role stereotypes in advertisements, where he defined a frame as the principles of organization which govern social events and our involvement in them (Hovland et al., 2005). Goffman coded the portrayals of women in advertisements into six categories: Relative Size - women are smaller or lower in comparison to men; Feminine Touch - women are shown caressing or touching objects or themselves; Function Ranking - women in occupational positions are shown subordinate to men; Family Scenes - women are portrayed as mothers and caretakers; Ritualization of Subordination - women are depicted in flirtatious or childish poses; and Licensed Withdrawal - women are portrayed as distracted or not involved in their surroundings. Though he handpicked advertisements from magazines that depicted these stereotypes, aspects of Goffman's coding scheme are still relevant today. When examining mobile phone advertisements, Doring and Poschl (2006) found that women were depicted using Feminine Touch more often than men, were engaged in subtle aspects of Licensed Withdrawal and Ritualization of Subordination more often than men, and were more likely to fulfill decorative roles and be shown in relaxing settings while men were shown doing paid work or involved in activities and sports. Women were also more likely to be objectified in these advertisements (show more skin), which is another code added by Kang (1997), who also reported that women are rarely shown outside of the home or as professionals, are often dependent on men and portrayed as sex objects, and are typically promoting low-cost items in her comparison of ads from 1971 and 1991. Though the advertisements in the Doring \& Poschl (2006) study did not portray women 
engaging in all of Goffman's coded behaviors, subtle aspects of them were present, suggesting that the stereotypes are still relevant, but possibly less evident.

Lindner's 2004 study supports this idea of subtle stereotyping. By examining magazine advertisements from 1955 to 2002, in both general interest (Time) and fashion magazines (Vogue), Lindner hypothesized that there would be an increase over time in Feminine Touch, Ritualization of Subordination, Licensed Withdrawal, Body Display, and Objectification because these behaviors are typically associated more with sexualized images of women and more subtle stereotypical behaviors. According to Sullivan \& O'Connor's (1988) comparison of magazine ads from the 1950s and 1970s to ads from 1983, advertising more accurately reflected women's social roles and occupations, but this was counterbalanced by an increase in presenting women in more decorative and sexualized roles, which worked to reestablish the power balance between the genders. Taking this change in the types of stereotypes presented into consideration, Lindner coded the portrayal of women in magazine ads in the following categories: Relative Size, Function Ranking, Feminine Touch, Ritualization of Subordination, Licensed Withdrawal, Body Display, Movement (the woman's movement is inhibited, limiting the amount of control she has on the environment), Location (domestic or decontextualized), and Objectification. She found that stereotyping occurred most often by objectifying women, showing women as subordinate to men, and depicting women as mentally withdrawn from the environment, and she argues that these depictions show women associated with lower levels of control. Decreases in Feminine Touch, Ritualization of Subordination, and Movement were found over time. The extent to which women were portrayed in the behaviors associated with the other coding categories remained fairly 
constant over time. However, magazines that portrayed women stereotypically in regards to Relative Size were less likely to portray them in any other stereotypical manner. Overall, $78 \%$ of the magazine ads studied showed women stereotypically in at least one category, suggesting that gender role stereotypes, though slightly different, still exist in contemporary advertising.

The existence of these stereotypes is important because they not only occur in general interest magazines, but also in magazines geared toward women exclusively. Women were portrayed more stereotypically in women's magazines than general interest magazines (Lindner, 2004), and women's magazines bring an estimated 40 million women to advertisers each month (Mastin et al., 2004). Although magazines are mainly vehicles for consumption, many women consider them trustworthy sources of information that are geared directly to their needs, specifically in home maintenance and health information (Mastin, et al., 2004). Catering directly to women's needs in women's magazines seems fitting as advertising is sold corresponding to the demographics of the audience expected to view it. Gender is often used as a segmentation strategy because it is easily identifiable, gender segments are accessible, measurable, and responsive to marketing elements, and they are large and profitable (Darley \& Smith, 1995; Wolin, 2003).

There are assumptions that women make certain types of purchases according to these segments, which are seen in advertisements. Advertisements in Essence and Ladies' Home Journal featured products associated with personal and home physical appearances more often than products associated with financial services, major home appliances and furniture, technology, and transportation - products typically associated 
with purchase decisions made by males (Mastin et al., 2004). In fact, $0.5 \%$ of ads in Ladies' Home Journal featured financial or technology products. Only $2 \%$ of ads in Essence featured financial services and $1 \%$ featured technology products. The lack of technology and financial products and services in women's magazines further perpetuates the stereotype that women are typically only involved in purchase decisions involving low-cost items that relate to appearance (of themselves, their children, and their homes). Although women's social and domestic roles have changed over time with increases in divorce rates, women entering the job market, and the age at which women get married, purchase decision behavior is still presented as gender-based. "Advertising images printed in women's magazines that portray product purchase decision-making behavior as either primarily male- or female-based may subtly encourage female readers to idealize a life that espouses dependency on men despite documented decreasing marriage rates and dismal divorce statistics. That is, advertisements in women's magazines that portray specific purchase decision making behavior as gender-based is not only in stark contrast with the daily reality of many women, such advertisements may also serve to perpetuate patriarchal-sanctioned gender roles" (Mastin et al., 2004).

One must also consider the contradictions seen between advertisements and content in women's magazines. Often one will see recipes for succulent dinners and gooey desserts across the page from an ad for fitness equipment or diet programs, complete with toned and thin, Barbie-like models. Even those articles that promote good health and hygiene are found in the same magazine as cigarette and alcohol advertisements. What types of messages are being sent here? That we should be thin, fit, and healthy, but smoke two packs a day? Along the same vein, Gill (2007) argues that 
the traditional image of the "wife-mother-housewife" has been replaced with the "sexually assertive, confident, and ambitious women who express their freedom through consumption" - what Gill refers to as the superwoman. So although women are being seen more often as intelligent and accomplished with successful careers that allow them to buy, they should still be beautiful, wonderful hostesses and perfect wives and mothers.

The direct gender segmentation in advertising, the obvious stereotypical portrayals of women, and the assumptions of gender-based purchase decision-making have all led to the main question guiding the current research. It seems that advertisers are aware of the stereotypes, yet continue to produce advertisements featuring men and women engaging in certain behaviors with certain types of products. The fact that stereotypes are more prevalent in ads in women's magazines suggests that this technique of gender role stereotyping is successful in attracting and maintaining consumers. Therefore, the main research question - Why do advertisers continue to produce advertisements that portray gender roles stereotypically? - can be answered through the testing of six main hypotheses. It is assumed that the continual success of products featured in gender congruent advertisements cause advertisers to continue to produce advertisements that portray these stereotypes.

\section{HYPOTHESES}

Six main hypotheses have emerged that will guide this research and test the effectiveness of advertisements that portray gender role stereotypes. The first three hypotheses focus on attention to the advertisement by measuring perceived message clarity, perceived message believability, and argument quality. These three items were taken from the information-processing model developed by McGuire (1968). The main 
idea is that information is processed through six stages: exposure to the message, attention to and perception of the message, orientation or comprehension of the message, acceptance of the premises in the arguments or the degree of goal-directed processing, attributions which may lead to opinion change, and integration which may lead to attitude change. The information-processing theory relies on the premise that in order for persuasion to be accomplished, the viewer must pay attention to the message and understand the message. Once comprehension is accomplished, attitude change should be the result. Once exposed to a message, viewers will pay attention to it based on their level of involvement with the issue, product, argument, etc. Based on the amount of attention given to the message, viewers will then determine the clarity of the message which in turn influences the perceived argument quality and ad believability.

Hypothesis 1: The message in the gender congruent advertisements will be perceived as more clear than those in the incongruent advertisements.

Hypothesis 2: The message in the gender congruent advertisements will be perceived as more believable than those in the incongruent advertisements.

Hypothesis 3: The argument(s) made in the gender congruent advertisements will be perceived more favorably than the arguments made in the incongruent advertisements.

Figure 1: Information-Processing Model

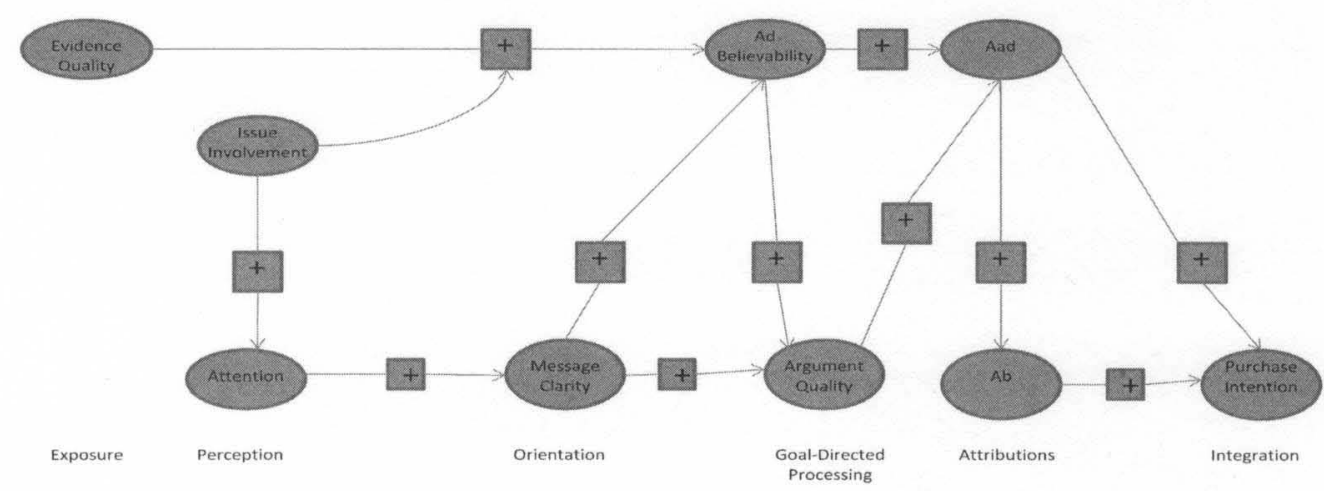


The last three hypotheses focus on advertising effectiveness by measuring attitude toward the brand, attitude toward the advertisement, and purchase intention.

The match-up hypothesis (Kamins, 1990; Till \& Busler, 2000) will be used to exhibit gender congruency and incongruency. The match-up hypothesis suggests that advertisements are more effective when there is a perceived match or fit between the endorser and the product. Typically, physical attractiveness is used as the match-up factor between a celebrity endorser and the product. In this study, however, gender will be used as the match-up factor, as previous research suggests there is a perceived fit between gender and products purchased.

Hypothesis 4: Gender congruent advertisements will be rated more favorably than gender incongruent advertisements.

Hypothesis 5: Brands in gender congruent advertisements will be rated more favorably than brands in the gender incongruent advertisements.

Hypothesis 6: Consumers will be more likely to purchase products in the gender congruent advertisements than those in the incongruent advertisements. To combine all hypotheses, based on the information-processing model, as long as the message is perceived as clear, perceived argument quality and ad believability should have a positive impact on attitude toward the ad, which should then influence attitude toward the brand. Attitude toward the ad and attitude toward the brand will then form the purchase intention.

\section{PRE-TEST}

Undergraduate students in two sections of an introductory level communication class were presented with a PowerPoint presentation during class to first determine what 
types of products are best associated with each gender. The products shown were selected to fit into one of five categories, and three products were shown for each category. The products were presented in a random order. The five product categories and the corresponding products were: Household products (showing a vacuum, a skillet, and laundry detergent), Child care products (showing a stroller, a play pen, and kids' shampoo), Technology (showing a cell phone, a stereo, and headphones), Tools (showing a power drill, a screwdriver, and a box of nails), and Home furnishings (showing a shelf, a foot stool, and a floor mat). The products and categories were selected based on price similarities and gender coding.

Each product was presented to the class in which they were asked to indicate by a show of hands if the product was masculine, feminine, or gender neutral (or would be more likely to be used by a male, female, or both). They were told the exercise was an example of polling the audience, a method of audience analysis, which pertained to the course curriculum.

The first class had 17 participants and the second class had 20, resulting in a total of 37 participants for this activity. Though the sample size was rather small, the numbers showed a strong disparity according to gender congruency such that a larger sample was not necessary. The results of the activity showed that the stroller was the most feminine product, with 26 of 37 total votes (one person voted masculine, 10 voted gender neutral). The power drill got 36 of 37 votes for masculine, with one person voting feminine. Therefore, the two products used for the final experiment are the stroller and the power drill. 


\section{MATERIALS}

Four electronic advertisements were created by the researchers using stock photos collected from an internet search (Figures A - D). Two ads were created for a power drill and two ads were created for a stroller. One power drill ad featured a male endorser and was labeled Gender Congruent Male (GCM). The other power drill ad featured a female endorser and was labeled Gender Incongruent Female (GIF). One stroller ad featured a male endorser and was labeled Gender Incongruent Male (GIM), while the other ad featured a female endorser and was labeled Gender Congruent Female (GCF). The product images were found by searching for "power drill" and "stroller." Once the images for the products were selected, models for each ad were selected. For the GCM ad, a search was conducted for a "male construction worker." For the GIM ad, a search was conducted for a "female construction worker." Two similar images were selected: both endorsers are shown at a construction site, both are shown using blueprints or plans, both are wearing hard hats, and both appear to be Caucasian. Searches for "man with toddler" and "woman with toddler" were conducted on the internet for endorsers for the GIM and GCF advertisements. Again, two similar images were selected: both show the children being embraced by the models, both children are boys, both endorsers appear to be Causcasian, and both images show the models actively interacting with the children.

The product name, Dawson, was made up and was used across all four advertisements, as was the made-up headline "Partner Up with Dawson." A sub-headline of "Because you can't go wrong with its dependability" was also added. A brief section of ad copy was written which describes the product and the brand as being dependable. The headlines and copy stayed consistent across all four advertisements aside from a few 
minor changes to make sure the copy coincided with the product. In other words, the two advertisements for the strollers only differed in the gender of the endorser, while the ads for the stroller and the power drill differed only slightly in the wording of the copy.

Each advertisement and a corresponding survey was then uploaded to Survey Monkey, a website allowing researchers and businesses to create, collect, and analyze survey data. Each ad and survey was assigned its own link and each link was assigned to a specific undergraduate class in which the instructor agreed to offer extra credit to his/her students upon completion of the survey. The four links were randomly distributed to nine different courses during a summer semester. The four links were distributed once more to six different classes during the following fall semester. The links were distributed via e-mail in a manner that would be most likely to yield even responses for each advertisement. For example, two courses had to be given two links because giving the entire class access to only one link would have resulted in more respondents viewing one ad, while not as many respondents viewed another ad. The goal was to obtain an equal amount of responses per advertisement.

\section{PROCEDURE AND PARTICIPANTS}

The sample for the main study consisted of undergraduates from the University of Louisville. Students from a variety of classes in the communication department volunteered to participate in exchange for extra credit. The point value for the extra credit received was determined by the instructor of the corresponding class. Of the 250 students who participated, $60 \%$ were females $(N=150)$ and $40 \%$ were males $(N=100)$. Of the four conditions, $51 \%$ of participants who viewed the GCM ad were female and $49 \%$ were male $(N=65) ; 61 \%$ of participants viewing the GIM ad were female and $39 \%$ 
were male $(N=57) ; 66 \%$ of participants who viewed the GCF ad were female and $34 \%$ were male $(N=65)$; and $63 \%$ of participants who viewed the GIF ad were female, while $36 \%$ were male $(N=63)$.

Subjects were randomly assigned to view one of the four advertisements, each of which represented one of two conditions: gender congruent and gender incongruent. Subjects were instructed to view and consider the ad as they would if they came across it while flipping through a magazine or other print publication. The target audience for all four advertisements is young adults, those beginning to make the transition from college to the "real world." Although the subjects may not be purchasing strollers or power drills immediately, these are purchases they may be starting to think about in the near future once they have families and homes of their own. All of the models in the ads appeared to be in their mid to late- twenties or early thirties, and all of the children featured were just reaching the toddler age.

It is important to note that gender congruency/incongruency was not tested prior to the main experiment to prevent participants from becoming familiar with the expected outcomes of the study. For example, respondents were not asked to indicate whether or not they felt the product matched the gender of the endorser in the advertisement. It was important that the respondents remained unaware of the hypotheses in order to obtain unbiased results. Respondents were expected to view and consider the ad as they would in a natural setting. If adherence to gender role stereotypes is something that influences the effectiveness of an ad on a person-by-person basis, consciously or unconsciously, it is assumed the results would indicate as much on their own. 


\title{
MEASURES
}

The six hypotheses were tested using six scales. Attention was measured first with three scales representing perceived message clarity, ad believability, and perceived argument quality, respectively. A 15 -item, seven-point semantic-differential scale was used to measure perceived message clarity (Sohn, 2006). Reliability for the measure was high, showing internal consistency $(\alpha=.91)$. Ad believability (Sohn, 2006) was measured by a three-item, five-point Likert scale $(\alpha=.87)$, and perceived argument quality was measured using a 10-item, seven-point semantic differential scale $(\alpha=.92)$ (Petty \& Cacioppo, 1986).

Attitude toward the ad $(\alpha=.92)$ and attitude toward the brand $(\alpha=.94)$ were each measured using the same 10-item, seven-point semantic-differential scale, though the anchors on this scale were different than the anchors used to measure perceived argument quality (Madden, Allen, \& Twible, 1988). Purchase intention was then measured by a three-item, five-point Likert scale $(\alpha=.91)$ (Sohn, 2006). A brief demographic questionnaire was added at the end to test for any potential interaction effects. Subjects were given the opportunity to provide their gender, age, and ethnicity. (See Appendices A - F for all measures.)

\begin{abstract}
ANALYSIS
Although four advertisements were used to create four conditions, data for both gender congruent ads and data for both gender incongruent ads were combined to form one gender congruent condition and one gender incongruent condition. An independent samples $t$-test was then conducted to test the effects of gender congruency on each of the six dependent variables, corresponding to each of the six hypotheses. Therefore, analyses
\end{abstract}


were conducted to determine if gender congruency has a significant effect on perceived message clarity, ad believability, perceived argument quality, attitude toward the ad, attitude toward the brand, and purchase intention.

\section{RESULTS}

Results for each hypothesis were recorded following the independent samples $t$ test.

Perceived Message Clarity: $\mathrm{H} 1$ stated that gender congruent advertisements would be perceived as more clear than those in the incongruent advertisements. The result of an independent samples $t$-test showed a significant difference for gender congruency $(M=4.97, S D=.92)$ and gender incongruency $(M=4.58, S D=1.04)$ on the perceived message clarity; $t(222)=2.98, p<.01)$. Messages in gender congruent advertisements were perceived as more clear than messages found in gender incongruent advertisements, thus supporting the fourth hypothesis.

Advertisement Believability: $\mathrm{H} 2$ predicted that the brands in gender congruent advertisements would be perceived as more believable than those in the incongruent advertisements. The result of an independent samples $t$-test showed no difference for gender congruency $(M=4.46, S D=1.25)$ and gender incongruency $(M=4.40, S D=$ $1.35)$ on ad believability; $t(247)=.32, p=.748$. Gender congruent advertisements were not seen as more believable than gender incongruent advertisements. The fifth hypothesis was not supported.

Perceived Argument Quality: H3 predicted that the argument(s) made in the gender congruent advertisements would be perceived more favorably than the arguments made in the incongruent advertisements. The result of an independent samples $t$-test 
showed no significant difference for gender congruency $(M=3.88, S D=1.19)$ and gender incongruency $(M=3.77, S D=1.30)$ on argument quality; $t(235)=.659, p=.511$. The arguments made in gender congruent advertisements were not rated more favorably than the arguments made in the gender incongruent advertisements. The sixth hypothesis was not supported.

Attitude toward the Advertisement: $\mathrm{H} 4$ predicted that the gender congruent advertisements would be rated more favorably than gender incongruent advertisements. The result of an independent samples $t$-test showed no significant difference for gender congruency $(M=3.60, S D=1.29)$ and gender incongruency $(M=3.40, S D=1.26)$ on attitude toward the ad; $t(239)=1.27, p=.21$. Gender congruent advertisements were not rated more favorably than gender incongruent advertisements. The first hypothesis was not supported.

Attitude toward the Brand: H5 predicted that the brands in gender congruent advertisements would be rated more favorably than the brands in the gender incongruent advertisements. The result of an independent samples $t$-test showed no significant difference for gender congruency $(M=3.73, S D=1.36)$ and gender incongruency $(M=$ $3.50, S D=1.39)$ on the attitude toward the brand; $t(230)=1.27, p=.20$. Brands in gender congruent advertisements were not rated more favorably than brands in gender incongruent advertisements. The second hypothesis was not supported.

Purchase Intention: H6 predicted that the consumers would be more likely to purchase products in the gender congruent advertisements than those in the incongruent advertisements. The result of an independent samples $t$-test showed no significant main differences for gender congruency $(M=2.71, S D=1.59)$ and incongruency $(M=2.52$, 
$S D=1.53$ ) on purchase intension; $t(246)=.98, p=.326$. Respondents were not more likely to purchase products shown in gender congruent advertisements than products shown in gender incongruent advertisements. The third hypothesis was not supported.

\section{POST HOC ANALYSIS}

A post hoc analysis was conducted following the main experiment to test for interaction effects between gender congruency and the sex of the participants. A oneway ANOVA was performed for each dependent variable to test for main effects of gender congruency on perceived message clarity, advertisement believability, and perceived argument quality, attitude toward the advertisement, attitude toward the brand, purchase intention. The ANOVA showed that perceived message clarity was the only variable affected by gender congruency, confirming the results of the $t$-test. H4 stated that gender congruent advertisements would be perceived as more clear than those in the incongruent advertisements. The result of the ANOVA showed a significant main effect of gender congruency on the perceived message clarity, $F(3,220)=3.33, p<.01$.

A two-way ANOVA was performed for each dependent variable to test for interaction effects between gender congruency and the sex of the respondents. The ANOVA did now show any interaction effects between the gender congruency presented in the advertisements and the sex of the respondents who viewed each advertisement. A two-way ANOVA was also performed for each dependent variable to test for interaction effects between gender congruency and the sex of the model shown in each advertisement. Again, the ANOVA did not show any interaction effects between gender congruency and the sex of the models in the ads. 


\section{DISCUSSION}

This study found that, despite previous research in advertising and gender role stereotypes, gender congruency has little impact on advertising effectiveness. Of the six dependent variables tested, gender congruency only produced significant results for perceived message clarity; those viewing a gender congruent advertisement perceived the message as more clear than those viewing a gender incongruent advertisement. Gender congruency had little effect on ad believability, argument quality, attitude toward the ad, attitude toward the brand, and purchase intention. That is, the gender of the featured model in each advertisement had little impact on responses toward the advertisements regardless of the product being promoted.

Although the results showed little effect between gender congruency and advertising effectiveness, one very important conclusion can still be drawn from the results of this experiment: gender role stereotypical advertisements do not necessarily increase or enhance advertising effectiveness, specifically with low-involvement products. We can, therefore, conclude that advertisers may not need to focus as much of their efforts on portraying gender stereotypes in their ads to sell lower-involvement products. In this case, they are only perpetuating such stereotypes for very little, if any, benefit. The results from this study take a first step in indicating that portraying gender role stereotypes in advertisements is less important and effective than advertisers may think.

Previous research suggested advertisers use gender as a specific segmentation strategy (Dines \& Humez, 1995; Schumann, 2004), targeting women for certain types of products and services that fit into a certain category of stereotypically feminine, as was 
the same with men. Images of men and women are used to attract attention and persuade, but these images are typically drawn from a very narrow and concentrated pool, which often rely heavily on stereotypical displays of gender. These images portray representations of the way we think men and women behave, not necessarily the ways in which they actually behave (Jhally, 1995). The types of products advertised in magazines targeting women also fit the gender role stereotype phenomenon as these products are usually those associated with the home, taking care of a family, or physical appearance. When the female magazine market grew in the 1980s and 1990s, as women were beginning to work outside the home and could no longer be targeted through daytime TV commercials, two important trends began to emerge. First, was the expansion of fashion to all other areas of life. Fashion was no longer about physical appearance of the self anymore, but about fashioning space without seeming boastful about it. The second trend was the linking of lifestyles to celebrity culture. The idea here was to make celebrities seem more like "real" people who had to deal with the same things women have to deal with every day, just with a bigger income. (Giddens, 1991). InStyle magazine is an example of “'filtering' the classic women's magazine format of fashion, beauty, home decorating, food, and fitness information through the lives of celebrities" (Giddens, 1991).

Because men and women buy products advertised in this manner, which indicate a successful and effective advertisement, it was assumed that the endorser should match the product in the advertisement according to a gender role stereotype. The gender role stereotypes portrayed in this study were that women typically take care of the kids and would therefore more likely be associated with a stroller, and that men do more 
handiwork and would be more likely to work in a construction-related field than women, making them more likely to purchase and use a power drill.

The results seem to indicate, however, that these gender roles and associated stereotypes are outdated and perhaps no longer necessary for advertising products. Based on the results of this study, advertisers should consider re-evaluating their current strategies of depicting men and women engaging in gender-stereotyped activities or endorsing gender-stereotyped products. Male and female respondents in this particular study rated the ads no more or less favorably regardless of the gender congruency between the endorser and the product. For example, respondents did not seem to be "put off' by a male in an ad for a stroller or by a female in an ad for a power drill.

One possible explanation for these limited effects of gender congruency may have something to do with the positioning of the products in the advertisements. Products in the gender incongruent advertisements may have been perceived as masculine and feminine simply because respondents perceived the setting or mood (positioning of the product) as masculine or feminine. For example, men would be likely to consider a stroller a feminine product even when viewing the GIM ad because of existing stereotypes that lead people to automatically associate a stroller with a caretaker, and both with femininity. The copy for all four advertisements emphasized dependability in the product and brand endorsed. However, the copy for the stroller ads claim that spending the day with your child is easier and more fun with the light but tough stroller, while the copy for the power drills claim that work projects are simpler to complete due to the light but powerful design. Both ads emphasize dependability, durability, ease of use, and strength, but one might get a warmer and more nurturing feeling from the 
stroller ad simply because of the associations that exist between femininity, nurture, and family. Women, then, would still be likely to see the power drill as a masculine product even though the endorser for the GIF advertisement was a female. Because the respondents were not given the opportunity to compare a gender congruent advertisement to a gender incongruent advertisement before rating the effectiveness of the advertisement, it is possible that they perceived such ads and products as masculine or feminine simply because they were perceived to be positioned as such due to existing stereotypes and cultural scripts for masculinity and femininity, which is what the current study hoped to bring light to. As mentioned before, however, allowing respondents to view both a gender congruent and a gender incongruent advertisement could have influenced the results, as participants could have become aware of the purpose of the study.

A study by Kanungo and Pang (1973) found that products were perceived as being of higher quality when the gender of the model and the gender of the product were consistent during the promotion of the product. Specifically, men and women perceived cars more positively when they were promoted by men rather than by women and sofas were perceived more positively when promoted by women rather than men. Based on this, Bellizzi and Milner (1991) focused on the positioning of a traditionally maleoriented or masculine product - car care service - using radio commercials. By manipulating the copy of the commercial, the researchers positioned the product as explicitly masculine, explicitly feminine, or masculine-feminine balanced. A significant interaction was found between the gender position of the service and the gender of the receiver. Women responded more positively to the female-explicit position, while men 
responded more positively to the male-explicit position. Both men and women responded positively to the male-explicit position as well, but not to the female-explicit position, where men typically rated that commercial much more negatively. This study shows that although a car care service is used by both men and women (just as a stroller and a power drill might be), it is still typically associated with masculinity or with men, but both may see it as a more feminine service when it is positioned as such. The results from the current study, as well as the supporting studies, show that regardless of the gender of the endorser of a particular product, audiences may still associate certain themes and activities with each gender. Work, specifically that done with one's hands, is still associated with masculinity while childcare and the family are still roles associated with femininity.

This study, then, serves as an educational one for both advertisers and consumers. There are elements aside from gender congruency that contribute more to the effectiveness of an advertisement and these are the elements on which advertisers should focus. Selling the product should be the primary concern, rather than selling a gender stereotypical image. And, because individuals are bombarded with so many images and messages each day, perhaps creating ads that do not portray gender role stereotypes will set an example for our society as a whole. Although there has been progression toward equality between men and women, and women have become more independent and have stepped outside of the home, inequalities still exist and society still deems certain characteristics, attitudes, and behaviors as acceptable over alternative ones. For example, when interviewing for jobs, women are often asked questions about their personal and family lives in an attempt to determine if they have or plan on having children while 
working at that company. Men, however, are not asked these types of questions because it is typically assumed that their careers will not be affected by family responsibilities (Brendel \& Ivy, 2004). Answers to these types of personal questions often influence whether or not a woman is hired within a particular company or for a particular position. If she is concerned with raising a family and taking care of her children, then how can she be serious about her career?

These inequalities that exist are socially constructed in that our culture has deemed certain characteristics, behaviors, and attitudes as normal and, therefore, more desirable than others, which includes appropriate displays of gender (Wood, 2009). Because advertising can be both a reflection of society and culture and a perpetuator of societal and cultural trends (therefore helping in socially constructing gender role stereotypes), advertisers have a responsibility to show reality for what it is and for what it could be. If advertisers used more gender neutral or non-stereotypical images in their ads, perhaps they could help contribute to a necessary shift in societal attitudes that men and women can and do engage in similar activities and, therefore, buy similar products. Single-parent households are not only headed by women anymore; many men have primary care for their children. Even in dual-parent households, men and women often share the household responsibilities while also working outside of the home full-time. Women have now stepped outside of the house and are focusing on careers and achieving corporate advancement. Some are independent and assertive, characteristics typically associated with masculinity (Wood, 2009). Ideas of what is "masculine" and what is "feminine" have changed over the years and it is the responsibility of the media, and advertisers specifically, to appropriately convey that. 
Consumers should also be aware that much of what they see in advertising reinforces and thus perpetuates ideas about what is appropriate for women and men through the use of stereotypical images, and that this does not necessarily have to be the case. Being aware of the use of these stereotypical images is crucial because stereotypes are only being reinforced through the continued use of such images, which limits exposure to other dimensions of a person or product. This limitation is especially true in print advertising because only one image is presented to audiences. If only one image is being shown, that leaves little room for other, counter- or non-stereotypical information (Schumann, 2004). At all times, consumers should question the images and messages, subtle and blatant, that they see that entice them to buy certain products. Why is it that only "choosy moms choose Jif"? This slogan itself indicates that Jif brand peanut butter is not only the best choice of peanut butter, but also that a good mother should want the best for her children and should, therefore, feed them Jif peanut butter. However, this statement also indicates that mothers are the ones responsible for making sure their children are properly cared for; there is no indication that good parenting is a responsibility of both mothers and fathers, thus reinforcing the stereotype that women are and should be the primary caretakers. Therefore, these images and representations of men and women in advertising have the very serious potential to reinforce stereotypical behaviors and attitudes, among viewers, toward men and women outside of the realm of the media and advertising (Schumann, 2004).

\section{LIMITATIONS AND FUTURE RESEARCH}

Even though the current study provides important insights on the use of gender stereotypical images in advertising and related implications, there are several limitations 
in the study that should be addressed. The first limitation is the sample itself. Although the participants were randomly assigned to experimental groups, a convenience sample of university undergraduates was used. Previous research has shown that people with a higher level of education have more open and egalitarian attitudes when it comes to gender roles (Brewster and Padavic, 2000; Kulik, 2002), which may make them less likely to be affected by gender congruency in advertisements. Twenge (1997) also found that masculinity increased in women as level of education increased in a study that took place from 1974 to 1995 . However, men did not necessarily change in regards to their adherence to feminine or masculine behaviors or characteristics. Calvo-Salguero et al. (2008) hypothesized that men will be more masculine and women will be more feminine when the education level is low. They also hypothesized that women with a lower level of education would be more feminine than women with a higher level of education and the same trend would be evident in men. No significant difference was found between men in regards to level of education and femininity/masculinity; however, women with a lower level of education were typically more feminine than women with higher levels of education, though no differences were found in regards to masculinity.

Similarly, Kulik (2002) found that the more educated male and female parents were, the more liberal their gender role attitudes were for themselves and for their spouses. Specifically, the more educated the mother was in this particular study, the more liberal her husband's attitudes toward gender roles with his attitudes being more liberal than her own. The same study found the same trend in relation to the number of hours the mother works. The more hours she works outside of the home, the more liberal her attitudes and her husband's attitudes toward gender roles. Both the level of education 
of the parents and the number of hours the mother worked outside the home had significant effects on the gender role attitudes of their children. The more educated the parents were and the more hours the mother spent working outside the home, the more liberal the children's attitudes toward gender roles. If the number of hours the mother works influences whether or not children hold gender role stereotypical views, then the same could be said about women in general. Women who work outside the home hold fewer gender role stereotypes than women who do not work outside the home. Since the number of women in the workforce has significantly increased over the years (or it has become common and acceptable for women to work outside the home), it can be assumed that the majority of respondents in the current study grew up with working mothers, are currently employed themselves, and/or are going to school in order to gain employment. If any of these is true, that could have a significant effect on the respondents' adherence (or non-adherence) to gender role stereotypes, thus making them less prone to gender role stereotypical images in the advertisements they saw.

The same conclusion can be drawn about the education level of parents. If parents with higher levels of education hold fewer gender role stereotypes, in turn influencing their children, then the children with higher levels of education (college) would hold fewer gender role stereotypes as well, which could be the case in the current research. Because the sample was taken from a university, respondents are already on their way to completing higher education. When considering that the ads were designed to target the demographic of young adults, however, this limitation becomes less of a significant issue. The ads still presented products that some of the respondents may already be purchasing, and at the very least, products that they may soon be purchasing. The ads appealed to the 
intelligent consumer's need for dependability and ease of use, therefore, the subjects used in this study were a good fit for testing advertising effectiveness using the ads created. More specifically, the student participants were recruited from classes in the communication department only. Though they were recruited from a variety of different communication courses, it is possible that the sample contained many communication majors, who may have been previously exposed to advertising practices, product categories, and even gender stereotypes that they encounter within the media. They could have previous experience in thinking critically about and evaluating advertising practices and media effects. However, many of the participants were enrolled in Public Speaking during this study, which is a general education requirement for all majors at the university. A more inclusive sample should be used in similar future studies to ensure a diverse sample.

A second limitation that could have influenced the results of this study is the types of products presented in each advertisement. A stroller and power drill are likely to be low-involvement products for many of the participants. Though the participants are approaching the age at which they may be thinking about families and home maintenance, and thus need to purchase a drill or a stroller, many of them are not there yet. The results of this study could have been different if products shown in the ads had been ones of high-involvement for the respondents. It is likely that if the participants had been more involved with products shown, it would have been more likely that they evaluate the advertisement more critically by paying more attention to the message, the argument, and the believability of the ad. Product-involvement is an important consideration for future studies on advertising effectiveness and gender congruency as 
the models presented could have different effects on responses to different advertised products.

A third limitation that could have influenced the results of this study is the quality of the advertisements used in the experiment. Each advertisement was created by the researchers using Microsoft PowerPoint, so the advertisements could have been perceived as lower quality because they were not professional, influencing the responses of the participants. However, even though the ads were of lower quality, they must have been perceived the same by viewers throughout all four conditions. If the independent variables of gender congruency and incongruency exerted significant influences despite ad quality, significant differences would have been seen in the responses to the advertisements. Because gender congruency/incongruency did not have a significant impact on the effectiveness of the ad, the quality of the ad was not a very significant problem.

Lastly, this study did not take age or racial and ethnic background of the participants into account, both of which could have impacted the results of a study such as this. In the future, similar studies could be performed to incorporate these demographic characteristics. As mentioned previously, all of the participants were undergraduate students and most were between the ages of 18 and 24. It may be beneficial to test the effectiveness of gender role stereotypes in advertisements on individuals of different age groups. For example, younger children may be influenced solely by their parents, as the primary caretaker often serves as a model for gender role behaviors and attitudes (Wood, 2009). By the time these children reach college, 
however, they would have had the opportunity to formulate their own understandings and opinions of gender roles and expectations of what is appropriate for males and females.

Race and ethnicity also often intersect with gender in that how individuals understand gender and its associated expectations is often affected by an individual's cultural background (Wood, 2009). Because the United States is comprised of a variety of races and ethnicities, it may be beneficial to examine how effective gender congruency/incongruency is between different racial and ethnic groups.

\section{CONCLUSIONS}

While respondents in this particular study perceived messages in gender congruent advertisements to be clearer than messages in gender incongruent advertisements, it can be inferred from this study that gender congruency has little influence over the effectiveness of an advertisement. Therefore, we can conclude that advertisers should reconsider their use of gender role stereotypes in their ads, based on the results of this study. The success of an advertisement does not rely on these types of images. By continuing to portray such stereotypes, however, advertisers are only perpetuating and reinforcing traditional images of what it means to be masculine or feminine or male or female by persuading consumers that buying these products will allow them to achieve an ideal of femininity or masculinity when there really is no set "ideal" for such. Images portraying gender roles penetrate the core of individual identity. Our understanding of who we are is often impacted by our understanding of ourselves as male or female. Advertisements have the power to communicate this through a single image, where often only a glance is needed (Jhally, 1995). Roles, however, are not fixed within any one individual and advertising often fails to reflect this reality. As consumers 
change - they grow older and acquire new responsibilities - so do their media habits (Bogart, 1967). For the advertiser, this means that s/he/they must teach each new generation of consumers what the parent generation knows. Each set of images, though tweaked here and there to keep up with the times, is simply a set of images that has been passed down from generation to generation. So rather than continuing to put forth stereotypical images of gender, why don't advertisers look for new ways of appealing to consumers by reflecting changes in gender roles as they occur within society? Such an action will help appeal to a new generation of consumers by reflecting the changes that are made and can be made in our culture.

Perhaps advertisers continue to portray gender stereotypical images because doing so is a seemingly simple way to gain attention. For example, when we meet a stranger we may make inferences about that person that help us figure out how to communicate with him/her (Bogart, 1967). It is easy to assume that a female is feminine and will take part in stereotypically feminine things like shopping, cooking, and caring. The same is true with males. We can automatically assume that all males are masculine and are interested in cars, sports, and beautiful women. The realities of many men and women do not reflect that idea and it is time for the media to adapt to these changes.

Consumers, however, are not always - and do not have to be - passive acceptors of the roles and images put before them. Although images of lifestyle categories created by advertisers help individuals understand themselves and their environment or culture, each individual takes part in "defining, maintaining, defending, and critiquing lifestyle constructions offered up by the mediated marketplace" (Giddens, 1991). Through communication and education on the types of images presented in this marketplace, 
consumers can become better aware of what these images symbolize and can better determine whether or not to accept or reject the roles presented through these images.

Sut Jhally has referred to advertising as "a discourse through and about objects" because advertising does more than tell us about the things that we purchase (Dines \& Humez, 1995). Advertising tells us how these things are connected to other important domains in our lives, legitimizing consumption as a way of life. According to studies done on quality of life, the things people perceive as making them happy are social in nature: having control over one's life, self-esteem, a happy and healthy family life, and good relationships and friendships. What advertising does is connect these ideas to products and services that we can purchase to achieve happiness (Jhally, 1995). And how does one gain self-esteem, a romantic partner, good friends, and family? By taking on and enacting cultural prescriptions of gender by buying what is sold through advertising images. Because it is doubtful that the advertising industry will make necessary changes in the immediate future, it is important that the consumers are aware of the effects of the images with which they are presented daily so that they can make informed choices about the products they purchase and not the images. 


\section{REFERENCES}

Bellizzi, J. A. \& Milner, L. (1991). Gender positioning of a traditionally male-dominant product. Journal of Advertising Research, June/July, 72-79.

Bogart, L. (1967). Strategy in Advertising. New York: Harcourt, Brace, \& World, Inc.

Brendel, J. M. \& Ivy, D. K. (2004). You've come a long way, baby ... Or have you? In P. M. Backlund \& M. R. Williams (Eds.), Readings in Gender Communication (pp. 8-16), Belmont, CA: Wadsworth.

Brewster, K., \& Padavic, I. (2000). Change in gender-ideology, 1977-1996: The contributions of intracohort change and population turnover. Journal of Marriage and the Family, 62, 477-487.

Calvo-Salguero, A., Garcia-Martinez, J. M. A., \& Monteoliva, A. (2008). Differences between and within genders in gender role orientation according to age and level of education. Sex Roles, 58, 535-548.

Carter, C. \& Steiner, L. (2004). Introduction to critical readings: Media and gender. Critical Readings: Media and Gender. (pp.1-10). Maidenhead, UK: Open University Press.

Connell, R. W. (1987). Gender and Power. Stanford, CA: Stanford University Press.

Courtney, A.E. \& Lockeretz, S.W. (1971). A woman's place: An analysis of the role portrayed by women in magazine advertisements. Journal of Marketing, 8, 92-95.

Darley, W.K. \& Smith, R.E. (1995). Gender differences in information processing strategies: An empirical test of the selectivity model in advertising response. Journal of Advertising, 24 (1), 41-56.

Dines, G. \& Humez, J. M. (1995). Gender, Race and Class in Media: A Test-Reader. Thousand Oaks, CA: Sage Publications.

Doring, N. \& Poschl, S. (2006). Images of men and women in mobile phone advertisements for mobile communication systems in selected popular magazines. Sex Roles, 55, 173-185. 
Gerbner, G. \& Gross, L. (1973). Cultural indicators: The social reality of television drama. Pennsylvania University, Philadelphia. Annenberg School of Communications.

Giddens, A. (1991). Modernity and self-identity: Self and society in the late modern age. Stanford, CA: Stanford University Press.

Goffman, E. (1979). Gender advertisements. Cambridge, Massachusetts: Harvard University Press.

Hovland, R., McMahan, C., Lee, G., Hwang, J., \& Kim, J. (2005). Gender role portrayals in American and Korean advertisements. Sex Roles, 53 (11/12), 887-899.

Jhally, S. (1995). Image-based culture: Advertising and Popular Culture. In G. Dines \& J. M. Humez (Eds.), Gender, Race and Class in Media: A Test-Reader (pp. 7787). Thousand Oaks, CA: Sage Publications.

Kamins, M.A. (1989). Celebrity and non-celebrity advertising in a two-sided context. Journal of Advertising Research, June/July, 24-42.

Kang, M. (1997). The portrayal of women's images in magazine advertisements: Goffman's gender analysis revisited. Sex Roles, 37, 979-996.

Kulik, L. (2002). The impact of social background on gender-role ideology. Journal of Family Issues, 23, 53-73.

Lindner, K. (2004). Images of women in general interest and fashion magazine advertisements from 1955 to 2002. Sex Roles, 51 (7/8), 409-421.

Madden, T. J., Allen, C.T., \& Twible, J. L. (1988). Attitude toward the ad: An assessment of diverse measurement indices under different processing 'sets'. Journal of Marketing Research, 25 (August), 242-252.

Mastin, T., Coe, A., Hamilton, S., \& Tarr, S. (2004). Product purchase decision-making behavior and gender role stereotypes: A content analysis of advertisements in Essence and Ladies' Home Journal. The Howard Journal of Communications, 15 , 229-243.

McLaughlin, T. L. \& Goulet, N. (1999). Gender advertisements in magazines aimed at African Americans: A comparison to their occurrence in magazines aimed at Caucasians. Sex Roles, 40, 61-71.

Milkie, M.A. (1994). Social world approach to cultural studies: Mass media and gender in the adolescent peer group. Journal of Contemporary Ethnography, 23, 354380 . 
Petty, R. E. \& Cacioppo, J. T. (1986). Elaboration likelihood model of persuasion. Advances in Experimental and Social Psychology, 19, 123-205.

Schumann, D. W. (2004). Media factors that contribute to a restriction of exposure to diversity. In L. J. Shrum (Ed.), The Psychology of Entertainment Media: Blurring the Lines Between Entertainment and Persuasion (pp. 233-251). Mahwah, NJ: Lawrence Erlbaum Associates.

Sohn, S. H. (2006). Body image and the advertising process: Dynamics of the body Imaging process and its impacts on how individuals process advertising messages. (Doctoral dissertation). University of Connecticut, Storrs, CT.

Sullivan, G.L. \& O'Connor P.J. (1988). Women's role portrayal in magazine advertising: 1958 - 1983. Sex Roles, 18, 181-188.

Till, B.D. \& Busler, M. (2000). The match-up hypothesis: Physical attractiveness, expertise, and the role of fit on brand attitude, purchase intent and brand beliefs. Journal of Advertising, $X X I X(3), 1-13$.

Twenge, J. (1997). Changes in masculine and feminine traits over time: A meta-analysis. Sex Roles, 36, 305-325.

Wolin, L.D. (2003). Gender issues in advertising - An oversight synthesis of research: 1970-2002. Journal of Advertising Research, March, 111-129.

Wood, J. T. (2009). Gendered Lives: Communication, Gender, and Culture. Boston: Wadsworth. 


\section{Partner Up with Dawson}

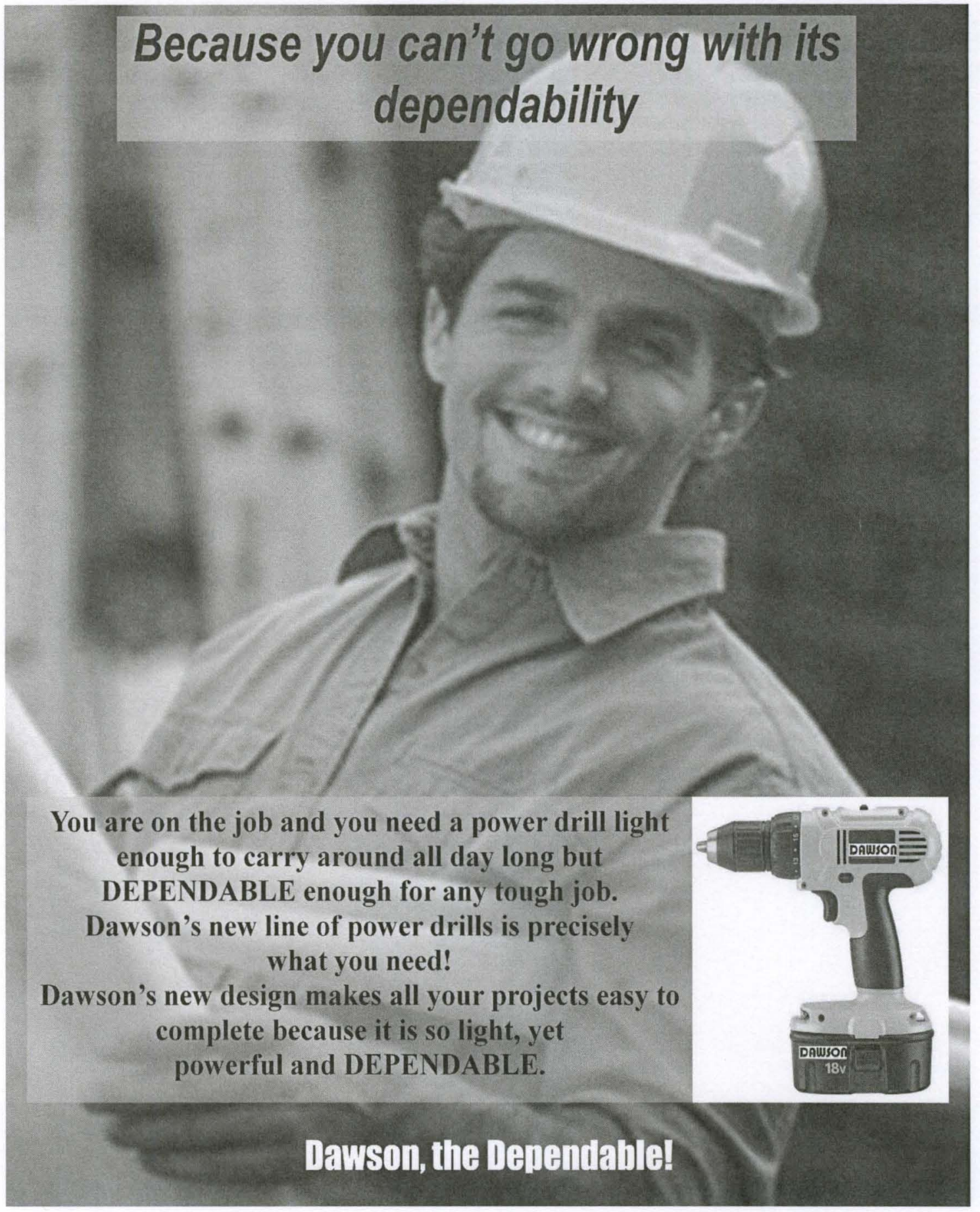


FIGURE B: GENDER CONGRUENT FEMALE ADVERTISEMENT

\section{Partner Up with Dawson}

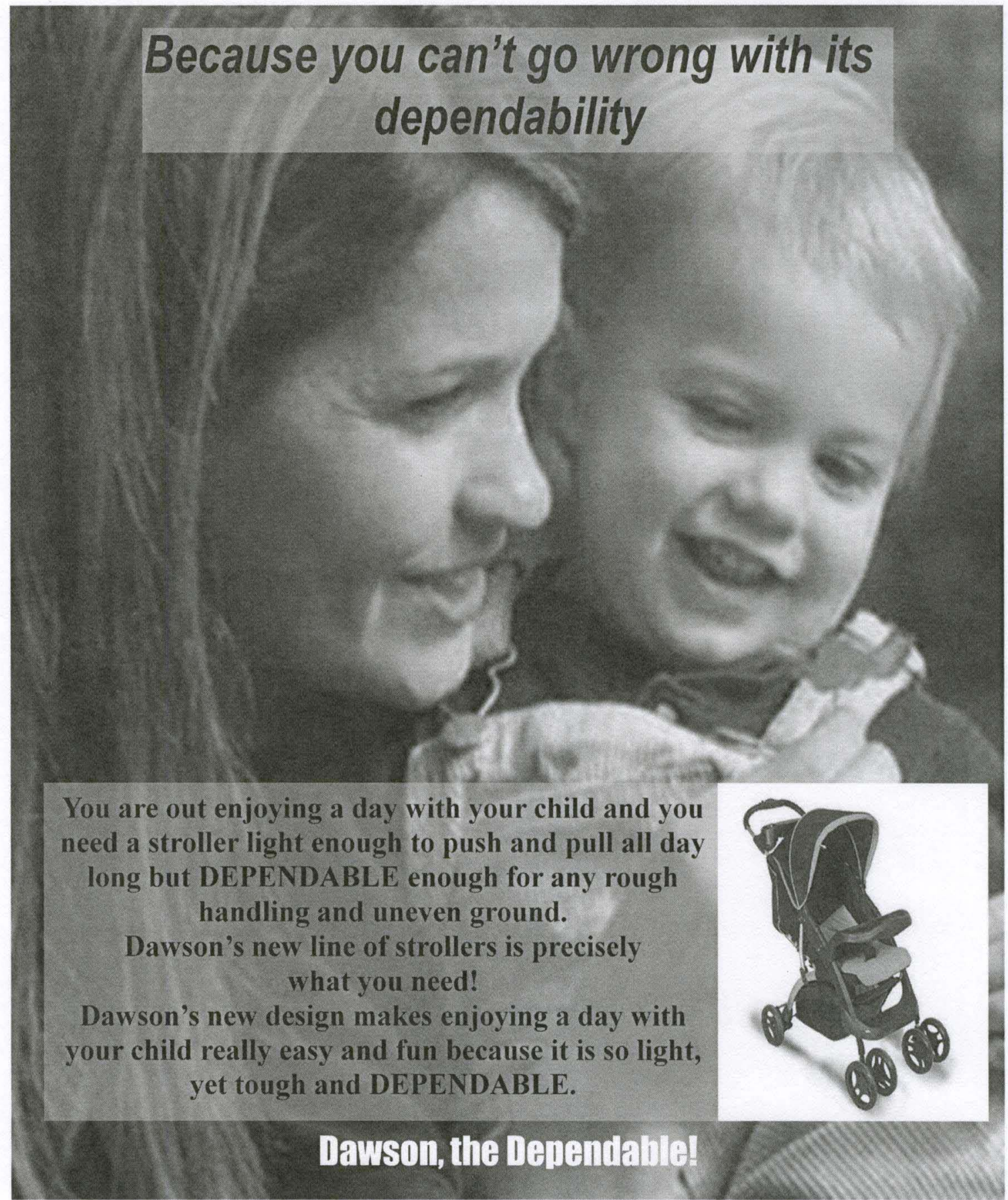


FIGURE C: GENDER INCONGRUENT MALE ADVERTISEMENT

\section{Partner Up with Dawson}

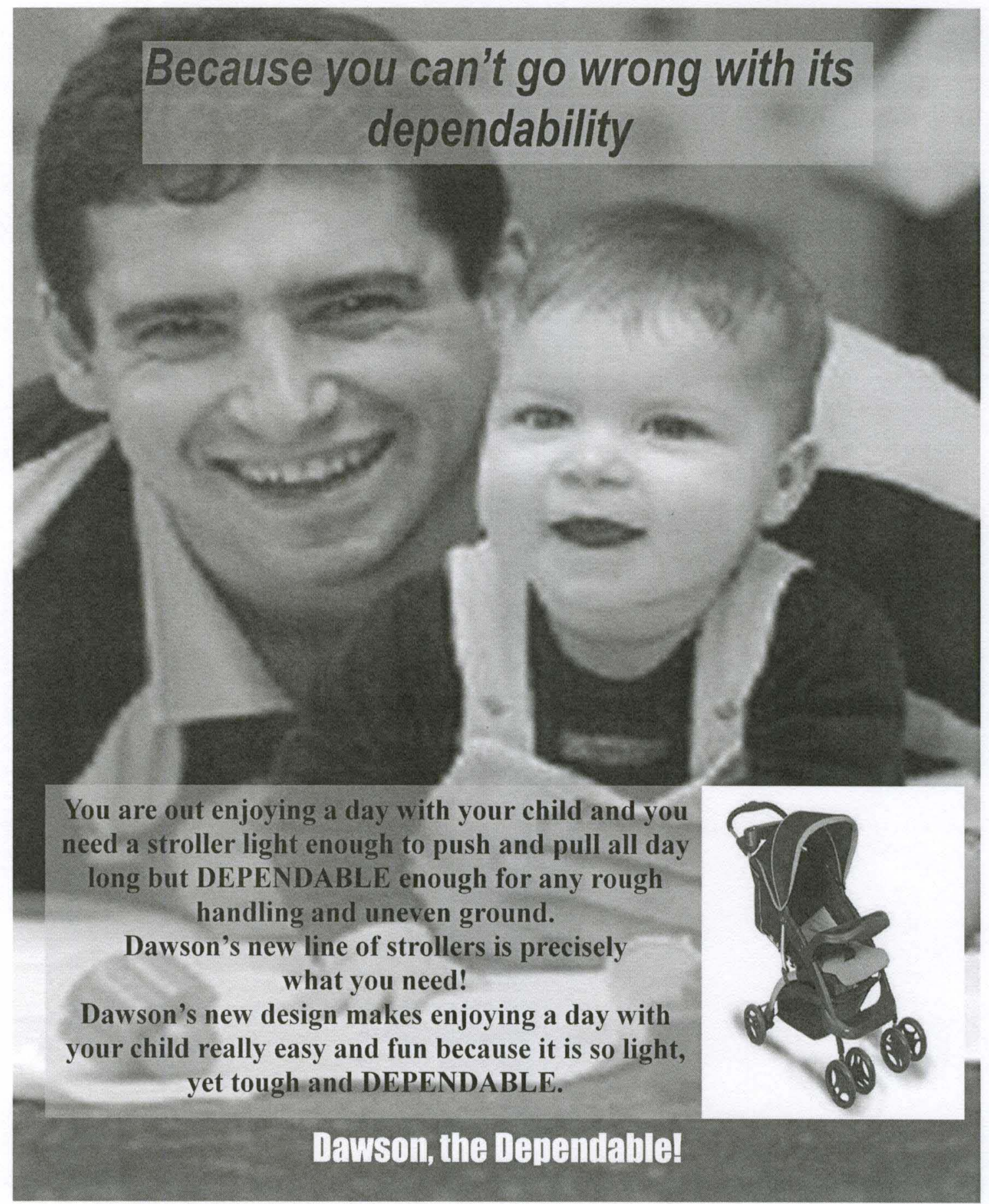




\section{Partner Up with Dawson}

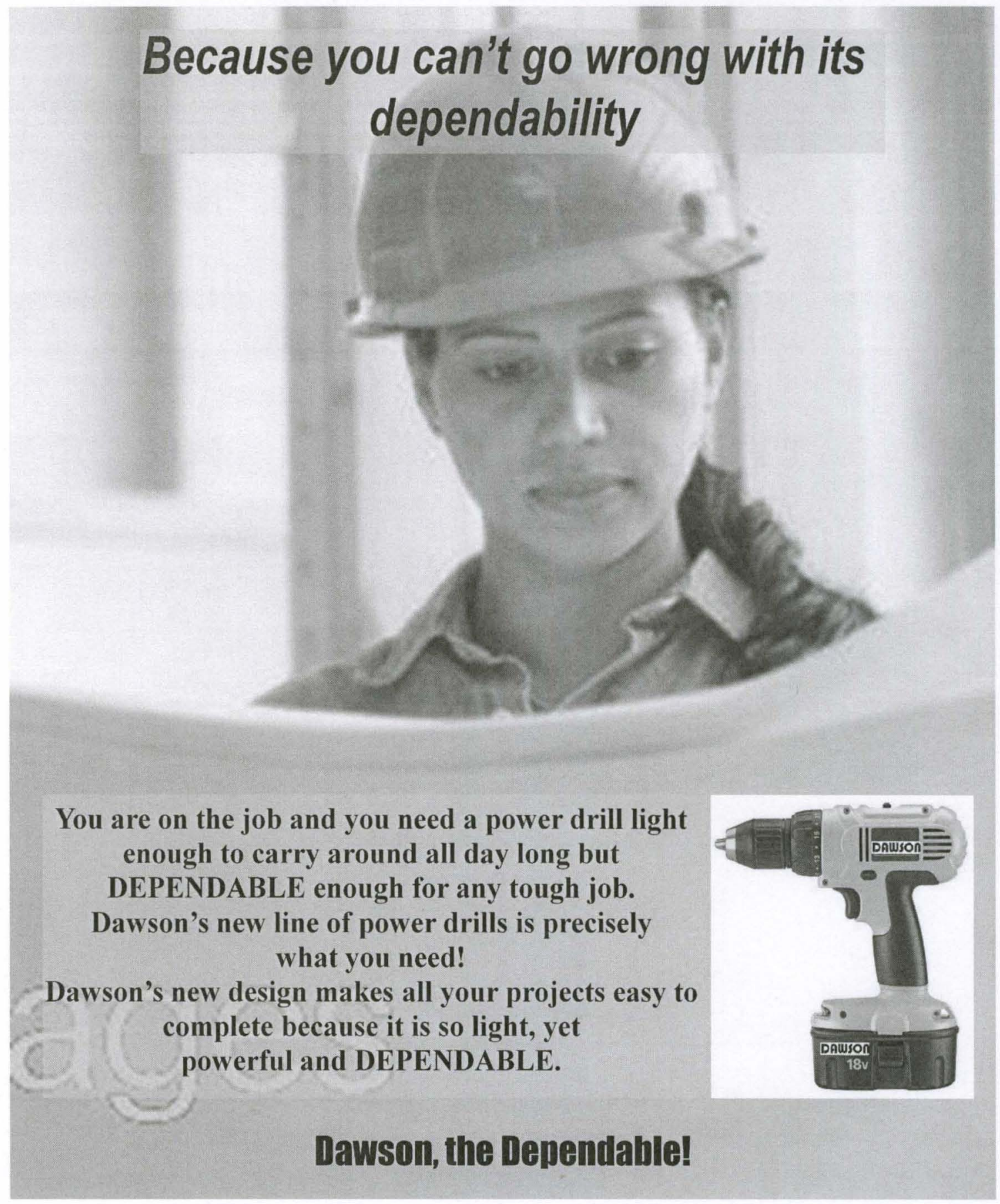




\section{APPENDIX A: PERCEIVED MESSAGE CLARITY}

Please indicate your overall reaction to the ad you just saw by circling the most appropriate number.

\begin{tabular}{|c|c|c|c|c|c|c|c|c|}
\hline Coherent & 1 & 2 & 3 & 4 & 5 & 6 & 7 & Incoherent \\
\hline Disorganized & 1 & 2 & 3 & 4 & 5 & 6 & 7 & Organized \\
\hline Effective & 1 & 2 & 3 & 4 & 5 & 6 & 7 & Ineffective \\
\hline Choppy & 1 & 2 & 3 & 4 & 5 & 6 & 7 & Smooth \\
\hline Direct & 1 & 2 & 3 & 4 & 5 & 6 & 7 & Indirect \\
\hline Awkward & 1 & 2 & 3 & 4 & 5 & 6 & 7 & Fluent \\
\hline Purposeful & 1 & 2 & 3 & 4 & 5 & 6 & 7 & Aimless \\
\hline Disorderly & 1 & 2 & 3 & 4 & 5 & 6 & 7 & Orderly \\
\hline Fragmented & 1 & 2 & 3 & 4 & 5 & 6 & 7 & Complete \\
\hline Vague & 1 & 2 & 3 & 4 & 5 & 6 & 7 & Specific \\
\hline Logical & 1 & 2 & 3 & 4 & 5 & 6 & 7 & Illogical \\
\hline Consistent & 1 & 2 & 3 & 4 & 5 & 6 & 7 & Inconsistent \\
\hline Confusing & 1 & 2 & 3 & 4 & 5 & 6 & 7 & Understandable \\
\hline Insensible & 1 & 2 & 3 & 4 & 5 & 6 & 7 & Sensible \\
\hline Clear & 1 & 2 & 3 & 4 & 5 & 6 & 7 & Not clear \\
\hline
\end{tabular}




\section{APPENDIX B: ADVERTISEMENT BELIEVABILITY}

Please indicate your reaction to the following statements by circling the most appropriate answer. $S D=$ Strongly Disagree, $D=$ Disagree, $N=$ Neutral, $A=$ Agree, SA = Strongly Agree.

1. I found the claim(s) made in the ad to be honest.
SD
$\mathrm{D}$
$\mathrm{N}$
A
SA

2. I found the claim(s) made in the ad to be believable.
SD
$\mathrm{D}$
$\mathrm{N}$
A
SA

3. I found the claim(s) made in the ad to be credible.
SD
D
$\mathrm{N}$
A
SA 
APPENDIX C: PERCEIVED ARGUMENT QUALITY

Please rate the quality of the arguments used in the ad by circling the most appropriate number.

$\begin{array}{lcccccccl}\text { Unconvincing } & 1 & 2 & 3 & 4 & 5 & 6 & 7 & \text { Convincing } \\ \text { Weak } & 1 & 2 & 3 & 4 & 5 & 6 & 7 & \text { Strong } \\ \text { Poorly constructed } & 1 & 2 & 3 & 4 & 5 & 6 & 7 & \text { Well constructed } \\ \text { Unbelievable } & 1 & 2 & 3 & 4 & 5 & 6 & 7 & \text { Believable } \\ \text { Ineffective } & 1 & 2 & 3 & 4 & 5 & 6 & 7 & \text { Effective } \\ \text { Not forceful } & 1 & 2 & 3 & 4 & 5 & 6 & 7 & \text { Forceful } \\ \text { Invalid } & 1 & 2 & 3 & 4 & 5 & 6 & 7 & \text { Valid } \\ \text { Illogical } & 1 & 2 & 3 & 4 & 5 & 6 & 7 & \text { Logical } \\ \text { Not compelling } & 1 & 2 & 3 & 4 & 5 & 6 & 7 & \text { Compelling } \\ \text { Unjustified } & 1 & 2 & 3 & 4 & 5 & 6 & 7 & \text { Justified }\end{array}$




\section{APPENDIX D: ATTITUDE TOWARD THE AD}

To me, the advertisement I just saw was:

Unappealing

Unimpressive

Unattractive

Unbelievable

Uninformative

Not clear

Not eye-catching

Unlikely

Unconvincing

Overall disliking $\begin{array}{lllllll}1 & 2 & 3 & 4 & 5 & 6 & 7\end{array}$

$\begin{array}{lllllll}1 & 2 & 3 & 4 & 5 & 6 & 7\end{array}$

$\begin{array}{lllllll}1 & 2 & 3 & 4 & 5 & 6 & 7\end{array}$

$\begin{array}{lllllll}1 & 2 & 3 & 4 & 5 & 6 & 7\end{array}$

$\begin{array}{lllllll}1 & 2 & 3 & 4 & 5 & 6 & 7\end{array}$

$\begin{array}{lllllll}1 & 2 & 3 & 4 & 5 & 6 & 7\end{array}$

$\begin{array}{lllllll}1 & 2 & 3 & 4 & 5 & 6 & 7\end{array}$

$\begin{array}{lllllll}1 & 2 & 3 & 4 & 5 & 6 & 7\end{array}$

$\begin{array}{lllllll}1 & 2 & 3 & 4 & 5 & 6 & 7\end{array}$

$\begin{array}{lllllll}1 & 2 & 3 & 4 & 5 & 6 & 7\end{array}$
Appealing

Impressive

Attractive

Believable

Informative

Clear

Eye-catching

Likely

Convincing

Overall liking 


\section{APPENDIX E: ATTITUDE TOWARD THE BRAND}

To me, the advertised brand in the ad I just saw was:

$\begin{array}{lcccccccl}\text { Unappealing } & 1 & 2 & 3 & 4 & 5 & 6 & 7 & \text { Appealing } \\ \text { Unimpressive } & 1 & 2 & 3 & 4 & 5 & 6 & 7 & \text { Impressive } \\ \text { Unattractive } & 1 & 2 & 3 & 4 & 5 & 6 & 7 & \text { Attractive } \\ \text { Unbelievable } & 1 & 2 & 3 & 4 & 5 & 6 & 7 & \text { Believable } \\ \text { Uninformative } & 1 & 2 & 3 & 4 & 5 & 6 & 7 & \text { Informative } \\ \text { Not clear } & 1 & 2 & 3 & 4 & 5 & 6 & 7 & \text { Clear } \\ \text { Not eye-catching } & 1 & 2 & 3 & 4 & 5 & 6 & 7 & \text { Eye-catching } \\ \text { Unlikely } & 1 & 2 & 3 & 4 & 5 & 6 & 7 & \text { Likely } \\ \text { Unconvincing } & 1 & 2 & 3 & 4 & 5 & 6 & 7 & \text { Convincing } \\ \text { Overall disliking } & 1 & 2 & 3 & 4 & 5 & 6 & 7 & \text { Overall liking }\end{array}$




\section{APPENDIX F: PURCHASE INTENTION}

Regarding the advertised product you just saw in the ad:

1. I will consider purchasing the advertised product.

$\begin{array}{lllll}\text { SD } & \mathrm{D} & \mathrm{N} & \mathrm{A} & \mathrm{SA}\end{array}$

2. I will consider purchasing the advertised product within the next 6-months.

$\begin{array}{lllll}\text { SD } & \mathrm{D} & \mathrm{N} & \mathrm{A} & \mathrm{SA}\end{array}$

3. I will recommend the advertised product to my friends.

$\begin{array}{lllll}\text { SD } & \mathrm{D} & \mathrm{N} & \mathrm{A}\end{array}$




\section{Curriculum Vitae}

\section{CURRICULUM VITAE}

for Personnel Actions

\author{
College of Arts and Sciences
}

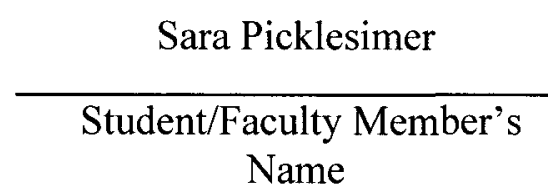

Name

$\frac{\text { COMMUNICATION }}{\text { Department }}$

December $/ 16 / 2010$

Date

Student/Faculty Member's

Signature

\section{EMPLOYMENT HISTORY:}

A. Academic Institutions other than University of Louisville

Institution Years

(Name and Location) of Service

Title of Position 
B. University of Louisville

Date appointed:

August 2009

Rank when appointed:

Graduate Teaching Assistant

Credit toward tenure when appointed?

None

Date tenured:

N/A

If currently untenured: date of tenure decision:

N/A

Promotion record:

N/A

Date of promotion to Assistant Professor:

N/A

Date of promotion to Associate Professor:

N/A

Date of promotion to Professor:

N/A

C. Other relevant employment. (Give title, type of work, location, dates and other pertinent information.)

- June 2006 -August 2009, Great American Cookie Co., Oxmoor Center, Louisville, KY

Sales leader

Managing shifts, interacting with customers, training employees

- August 2006 - January 2008, The Louisville Cardinal newspaper, University of Louisville

Chief Copy Editor

Editing copy from 5-6 sections before and after PDF for print, writing articles when needed, contacting/interviewing appropriate sources, verifying information

- June 2006 - August 2006, The UpSide of Talk radio show, WKJK 1080 AM, Clear Channel Communications, Louisville, KY

Intern/Assistant producer

Researching/preparing information for show topics, greeting and preparing guests before airing, writing proposals for promotional items, writing bios for show staff and clients for the show web site, aiding large projects, calling and meeting with clients, conducting conversations on air 
D. Honors received:

- December 2010, University of Louisville, Communication Department Outstanding Graduate Student

II. EDUCATIONAL HISTORY: (Undergraduate, Graduate, and Post Graduate)

Institution

(Name and Location)

University of Louisville

University of Louisville
Dates

Attended

Degree

MA

In progress
Fall 2008 - present

\begin{tabular}{lll}
\hline University of Louisville & Fall 2003 - Fall 2007 & BS \\
\hline
\end{tabular}

What is the most common terminal degree for academicians in your discipline:

Ph.D.

Other relevant training. Describe: 
III. TEACHING

A. Teaching, other than University of Louisville

Institution

(Name and Location)
Academic Rank

When Teaching
Courses Taught

B. Courses taught, University of Louisville, last 5 years (all courses are 3 credit hours):

$\underline{\text { Course \# }}$

COMM 111

Intro to Public Speaking

COMM 324

Gender and Communication $\underline{\text { Semesters Taught }}$

Fall 2009, Spring

2010, Fall 2010

Fall 2010

IV. SERVICE

V. RESEARCH AND CREATIVE ACTIVITY 